\title{
Shape Fastener of the Bus Skeleton Testing
}

\author{
Peter Pastucha ${ }^{1, a}$, Vladimir Ondek ${ }^{1, b}$, Filip Murgas ${ }^{1, c}$, Jan Rehor $^{2, d}$, Stanislav \\ Hosnedl ${ }^{2, e}$ \\ ${ }^{1}$ TU Kosice, Faculty of Manufacturing Technologies with the seat in Presov, Sturova 31, \\ 08001 Presov, Slovakia \\ ${ }^{2}$ University of West Bohemia, Faculty of Manufacturing Engineering in Pilsen, Univerzitni 22, \\ 30614 Pilsen, Czech Republic \\ apeter.pastucha007@gmail.com; 'bladimir.ondek@gmail.com; 'cfilip.murgas@centrum.sk;

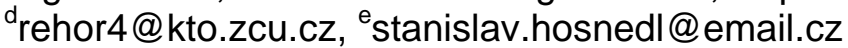

Keywords: shape fastener, bus skeleton, weld, finite elements method, mechanical load test Abstract. The paper deals with the bending tests of new designed joints for bus skeletons. The frames of buses have to satisfy various demands, but the safety of the passengers is the priority. The actual welded joints should be replaced by new type of profiles connections in the future. Finite elements method was used for the bending test simulation and for the stress investigation; the real experiments were done using the universal test equipment ZD10/90. Obtained results are comparable, so authors aim to realize next experiments in next days at which other shapes of the joints will be tested.

\section{Introduction}

The bus is defined as the motor vehicle designed for the transport of more persons and their luggage. The designing and manufacturing of new bus is a process which needs large number of technical labours and a great consumption time, starting from designing operation until full production process. Due to the high costs associated to the development of new vehicle models, computer simulations of vehicle dynamics become more and more important. While large multinational companies employ integrated design teams and the latest advances in computational technology and software using the economy of scale, many smaller companies are active in the design and construction of passenger buses according to local requirements and market specifications.

By appropriate structural design and used materials it is necessary to guarantee, next-to other requirements, the safety of each passenger. Stress and fatigue analysis of vehicle structures, prediction of service life and improvement of design are becoming more important areas of research activity. The strength of the base frame has to meet the legislative requirements. The skeleton is tested for the side-overturning resistance. In spite of the strict specifications it is not necessary to realize the tests on the whole frame of the bus, but the legislative rule includes the equivalent tests that can be done on the part of the all-metal structure. [1,2]

\section{Problem definition}

There are many types of the buses in the world; they differ in various indicators such as the size, power and construction. The skeleton of investigated bus is created by steel profiles (Fig.1a,b) that are usually welded using Metal Active Gas method. The base material of square (or rectangle) profiles with hollow sections is the low-carbon steel 11503 (STN 41 1503). The basic dimensions of the profiles are $40 \times 40 \times 80 \mathrm{~mm}$, the wall thickness is $3 \mathrm{~mm}$.

The right position of the profiles during the welding process is ensured by means of the jigs. Actually, the circumferential weld is used for profiles connection, but it has to be next processed by grinding to keep the plane surfaces at two opposite sides, as it is shown in the Fig. 1c. It cause that the weld is diminished; its load capacity is reduced and so the fatigue cracks or ruptures originate. 


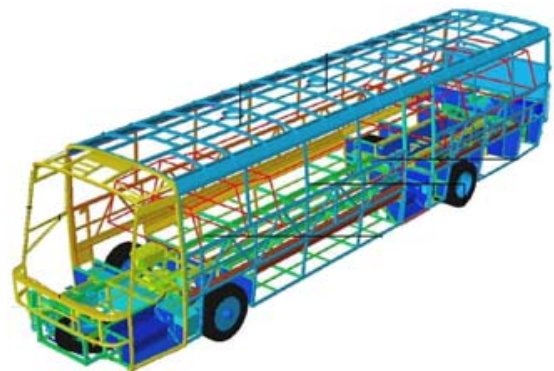

a) bus frame

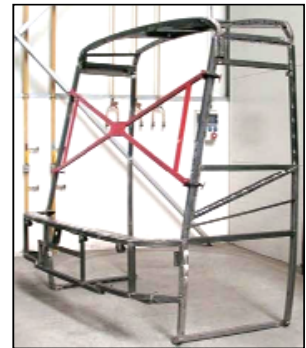

b) welded front panel

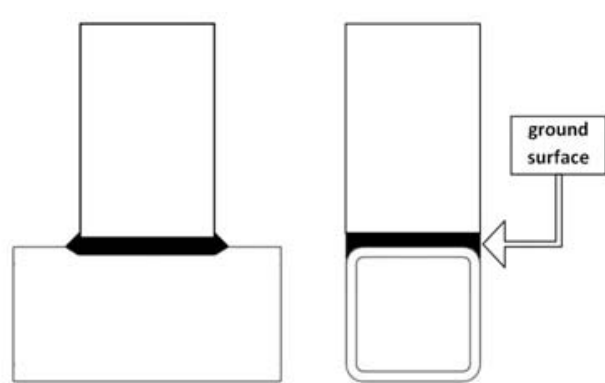

c) actual connection of the profiles

Fig. 1 Actual bus frame with detail of welded profiles

One of the eventual solutions of this problem consists in the replacement of some weld connection by the shape fasteners. The creation of these joints is possible thanks to the laser technology used at the material dividing that enables to create complex contours with high precision. [3,4] The example of new designed shape fastener (assembled and decomposed state) is in the Fig. 2.
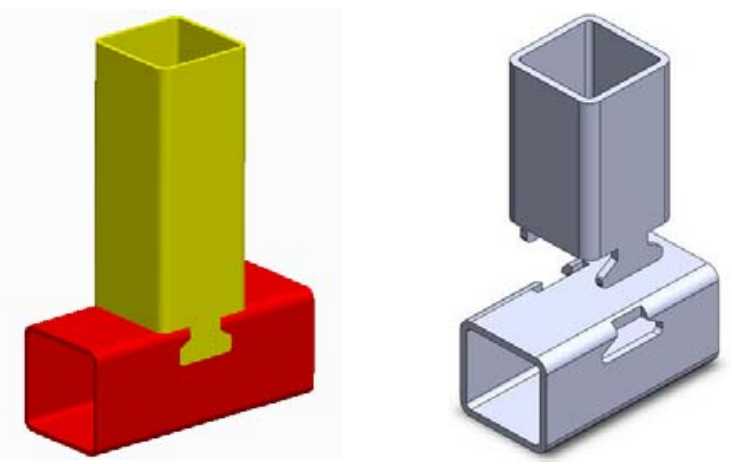

Fig. 2 New design of the shape fastener (assembled and decomposed state)

The 3D connection of the profiles mentioned above was tested numerically using FEM method and also experimentally.

\section{Bending tests}

Numerical method. The designed joint was loaded by bending moment represented by the force on the arm. At the analysis used Finite elements method (FEM) the non-linear material behaviour was considered, big displacements and contact non-linearity. For linear analysis the elastic isotropic model was used. Non-linear analysis requires the definition of von Misses plasticity and the lower yield point $\left(R_{p 0,2}=370 \mathrm{MPa}\right)$. [5,6,7] In the virtual environment of the computer the bottom profile was fixed, the top one was connected to the first component by means of the contact sets. The solution of this task required the mesh refinement in the contact area. The analysis was done in the software Cosmos Works that is the part of the software Solid Works.

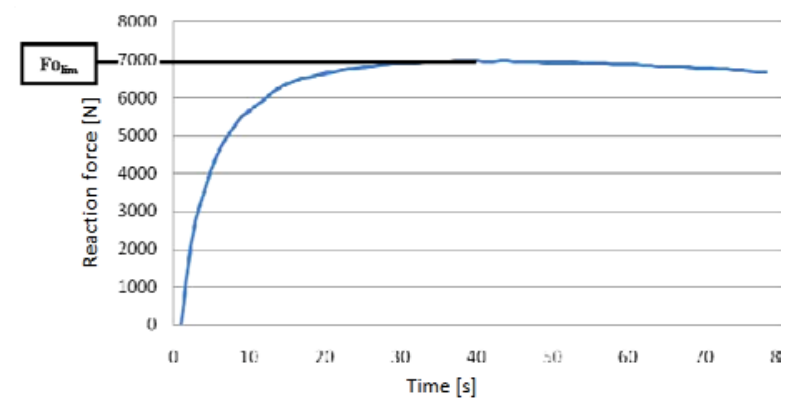

a)

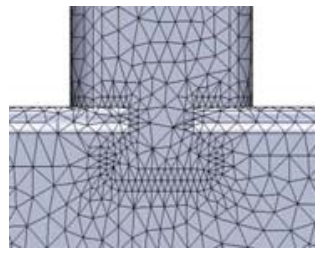

b)

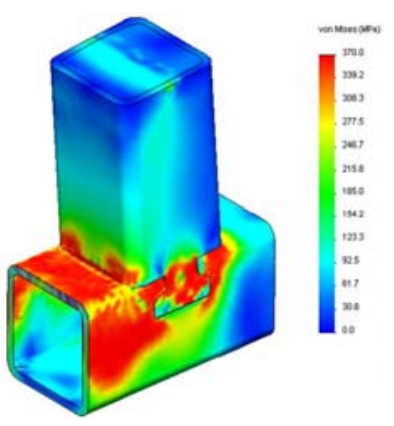

Fig. 3 Dependency of reaction force on time and Von Misses stress at the force $F z=6,9 \mathrm{kN}$

In the Fig. 3a is presented the dependency of the reaction force (acts on the bottom component) on the time. It is clear from this graph that the reaction force is increasing until it doesn't achieve the limit value followed by the loss of the stability and the load. The limit force can be deducted from the 
graph, it is $\mathrm{Fo}_{\text {lim }}=6,96 \mathrm{kN}$. Figure (Fig. 3b) shows von Misses stress distribution in the last time step of the analysis at the force $F o=F z=6,9 \mathrm{kN}$.

Experimental tests. Experimental bending tests were done due to the verification of the joint design and the numerical analysis results. At experiments the universal test equipment (shredder) ZD10/90 was used. The tested assembly of profiles was positioned by means of the fixture. The loading force was activated by the equipment head in the given distance $l=66 \mathrm{~mm}$. (Fig. 4)
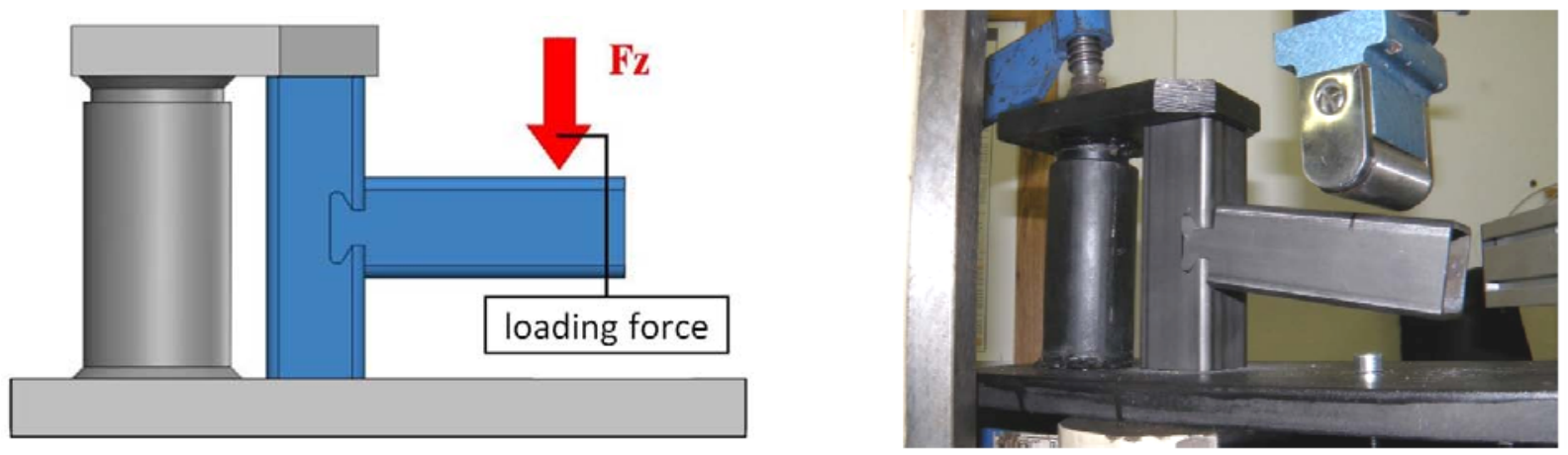

Fig. 4 Experimental bending test

The process of the test and the results are interpreted by graph in the Fig. 5. There is plotted the dependency of the loading force on the displacement of head equipment. The first phase describes the head movement without application of load until it achieve with the tested sample. Then the force increases to maximum $\mathrm{Fz}=6,401 \mathrm{kN}$. After overload the carrying capacity goes down, the force that is needed for the same displacement lowers and the tested sample is deformed, see the Fig. 5.
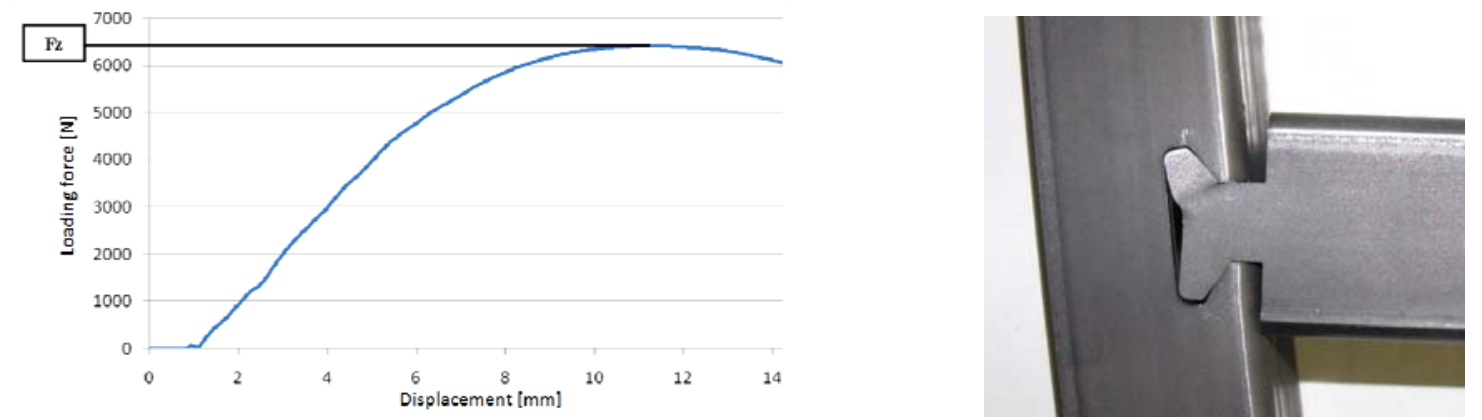

Fig. 5 Graph of the loading force and deformed tested sample

\section{Results and discussion}

The value of the investigated force obtained by FEM method was $F o_{\text {lim }}=6,96 \mathrm{kN}$ and the force achieved by experimental method was $\mathrm{Fz}=6,401 \mathrm{kN}$. The deviation between measures can be calculated on the base of following equation [8]

$$
\delta=\frac{F o_{\lim }-F_{z}}{F_{z}} 100=\frac{6,96-6,401}{6,401} 100=8,7 \quad[\%]
$$

It can be said that the results are comparable but the value about $6,4 \mathrm{kN}$ is not sufficient for real practice. It is clear that this type of connection is not to ensure against the biaxial moment of force, so the weld at minimal two opposite sides of profiles has to be made, as it is shown in the Fig. 6 .

Authors aim to realize next experiments at which other shapes of the joints and also welded profiles at opposite sides will be tested. 


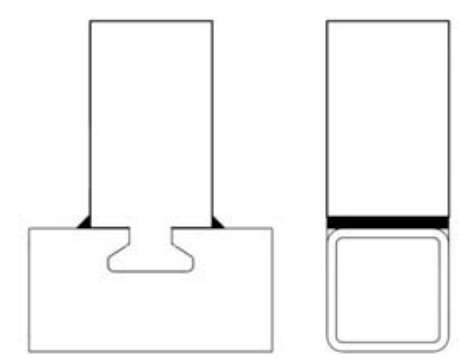

Fig. 6 Profiles welded at opposite sides

\section{Summary}

The design of the internal bus skeleton structure is the basis of typical bus development of the bus industry. It contains of framework of tubes with different cross sections, which arranged in specified shapes based on the design philosophy. This arrangement is used to be safe for occupants and to sustain the extreme conditions can be matched on the road. The bus body skeleton design represents the bottleneck stage within the industrial facility, which once completed successfully, the other company sectors starts to work either parallel or sequential. Thus, an acceleration of this process leads to a reduction of development time, which can be consequently transferred into money. In this way the industrial partner enhances its efficiency. Utilization of new connection, when it satisfies the safety regulations, should enable to reduce time of bus frame production in the future. [9] In spite of the fact that fasteners presented in the manuscript are not suitable for practical using, the tests and achieved results can be considered a first step to improve production efficiency.

\section{Acknowledgements}

This article originates with the direct support of Ministry of Education of Slovak republic by grants VEGA 1/0614/15, KEGA 013TUKE-4/2014 and KEGA 087TUKE-4/2015.

\section{References}

[1] Manokruang S., Butdee S.: Methodology of Bus-Body Structural Redesign for Lightweight Productivity Improvement. AIJSTPME Vol. 2/ 2 (2009), p. 79-87

[2] Monkova, K., Monka, P.: Newly developed software application for multiple access process planning. Advances in Mechanical Engineering (2014), p. 1-23.

[3] Hussein H. M. A., Harrich A.: Computer Aided Bus Skeleton Design. International Journal of Engineering \& Technology IJET-IJENS Vol.12/4 (2012), p. 113-117

[4] Kinik, D. et al.: On-line monitoring of technological process of material abrasive water jet cutting. Technical Gazette Vol. 22/ 2 (2015), p. 351-357

[5] Monkova, K. et al.: Kinematic analysis of quick-return mechanism in three various approaches. Technical Gazette Vol. 18/ 2 (2011), p. 295-299

[6] N. Ungureanu, et al.: Contributions regarding, the mining drilling tribo-system. Archives of mining sciences Vol. 56/3 (2011), p. 527-535

[7] Trebuna, F. et al.: Analysis of causes of casting pedestal failures and the measures for increasing its residual lifetime. Engineering Failure Analysis Vol. 29 (2013), p. 27-37

[8] Hreha, P. et al.: Determination of vibration frequency depending on abrasive mass flow rate during abrasive water jet cutting. International Journal of Advanced Manufacturing Technology Vol. 77/ 1-4, (2015), p. 763-774

[9] Monkova, K. et al.: Inverse processing of undefined complex shape parts from structural high alloyed tool steel. Advances in Mechanical Engineering (2014), p. 1-11 